\title{
Avaliação em Educação Especial: o ponto de vista do professor de alunos com deficiência
}

\author{
ANNA AUGUSTA SAMPAIO OLIVEIRA \\ Doutora em Educação (Unesp) e docente da Faculdade de Filosofia e \\ Ciências/Unesp, Marília \\ hanamel@marilia.unesp.br \\ THAÍS EMILIA CAMPOS \\ Pedagoga habilitada em Educação Especial (Unesp), especialista em \\ Psicopedagogia. Professora de Educação Infantil e Educação Especial \\ thaisemilia@bol.com.br
}

\begin{abstract}
Resumo
Este trabalho teve como objetivo discutir a prática da avaliação do aproveitamento escolar do aluno com deficiência. Assim, foi realizada uma investigação sobre a prática concreta da avaliação educacional, verificando, junto ao professor especializado, quais os critérios e estratégias que caracterizam o processo de avaliação utilizado para subsidiar o trabalho pedagógico e as decisões sobre o destino escolar do aluno com deficiência. Para isto, foi formulado um questionário com questões fechadas e entregue para 79 professores habilitados e atuantes em uma das quatro áreas de educação especial (deficiência auditiva, física, mental e visual), em classes especiais, salas de recursos, classes comuns inclusivas do Ensino Fundamental e da Escola Especial da APAE. Desse total, foram recebidos 39 questionários respondidos. As respostas foram classificadas por meio de categorias analíticas e submetidas à apreciação de consultores. Os resultados apontam que não ocorreram diferenças significativas entre os diferentes professores, o que nos permite inferir que seja nas instituições especializadas, nas classes especiais ou classes comuns, ao avaliar os alunos, as preocupações dos professores parecem transitar sobre os mesmos aspectos, salvo pequenas diferenças marcadas pelos objetivos específicos dos recursos educacionais dos quais os alunos são usuários.

Palavras-chaves: rendimento escolar, alunos com deficiência, professor especializado, educação especial.
\end{abstract}

\section{Resumen}

Este trabajo ha tenido como objetivo discutir la práctica de la evaluación del aprovechamiento escolar del alumno con deficiencia. Se realizó una investigación sobre la práctica concreta de la evaluación educativa, comprobando, junto al profesor especializado, cuáles son los criterios y estrategias que caracterizan el método de evaluación utilizado para subsidiar el trabajo pedagógico y las conclusiones sobre el destino escolar del alumno deficiente. Se elaboró un cuestionario con preguntas cerradas que fueron entregadas a 79 
profesores capacitados en una de las cuatro áreas de educación especial (deficiencia auditiva, física, mental y visual) y en ejercicio en clases especiales, salas de recursos y clases comunes inclusivas de la Enseñanza Fundamental y de la Escuela Especial de APAE. De este total, 39 fueron contestados. Se clasificaron las respuestas a través de categorías analíticas y los resultados fueron estudiados por consultores. No se encontraron diferencias significativas entre ellos. Eso nos permite ver que, tanto en instituciones especializadas como en clases especiales o comunes, la preocupación de los maestros coincide en los mismos aspectos al evaluar a los alumnos, a excepción de pequeñas diferencias señaladas por los objetivos específicos de los recursos educativos utilizados por los estudiantes.

Palabras-clave: aprovechamiento escolar, alumnos con deficiencia, profesor especializado, educación especial.

\begin{abstract}
The aim of this paper is to discuss the evaluation of progress of students with some kind of impairment. Thus, an investigation about the concrete practice of educational evaluation was carried out to examine, with the aid of the specialized teacher, which criteria and strategies characterize the evaluation process used to inform pedagogical practice and decisions about such students' educational destiny. For this purpose, a questionnaire with closed questions was designed and submitted to 79 skilled teachers working in one of the four areas of special education (hearing, physical, mental and visual) in special classrooms, resource classrooms, inclusive and common classrooms in Fundamental Education and at the Special School APAE. From this total, 39 questionnaires were completed. The answers were classified according to analytical categories and submitted to the appreciation of consultants. The results showed that no significant differences occurred among the different teachers, which allows us to infer that whether in specialized institutions, in common or in special classrooms, teachers' concerns when evaluating their students seem to revolve around the same aspects, except for small differences due to specific goals of the educational resources the students use.
\end{abstract}

Key words: educational development, students with impairments, specialized teacher, special education. 


\section{INTRODUÇÃO}

A prática tradicional da avaliação em educação tem seguido paradigmas teóricos derivados de uma tradição psicométrica, reduzindo o processo avaliativo a técnicas estatísticas estáticas para verificação do aprendizado escolar e desempenho dos alunos em determinado conteúdo específico. Os padrões, geralmente, são normativos e estabelecidos pela média do grupo, desconsiderando-se outras variáveis presentes, tanto no processo de ensino e aprendizagem quanto no processo de avaliação.

Embora tenhamos avançado no conhecimento sobre avaliação, na prática ainda se tem valorizado mais o produto do aprendizado escolar do que o processo pelo qual a aprendizagem se efetiva.

Vários estudos em Educação e Psicologia vêm demonstrando uma crescente consciência em relação aos procedimentos avaliativos tradicionais e sua ineficiência no sentido de subsidiar planejamentos pedagógicos que respondam às necessidades e dificuldades dos alunos com baixo rendimento escolar (Sousa, 1995; Alencar et al., 1994; Carvalho, 1993; Hoffman, 1991).

A literatura aponta para abordagens alternativas de avaliação, evidenciando a distinção entre avaliação estática e dinâmica. Na avaliação estática, a situação é artificial, mecânica e enfatiza o produto da aprendizagem. A avaliação dinâmica envolve a relação interpessoal que se estabelece entre professor e aluno, valorizando o processo e tendo como objetivo conhecer as estratégias de aprendizagem utilizadas pelos alunos, possibilitando o conhecimento de informações mais precisas que ofereçam sugestões para o ensino (Lunt, 1995).

Segundo Luckesi (1990), a avaliação da aprendizagem escolar tem sentido somente quando está envolvida em um projeto pedagógico e com seu projeto de ensino, assim a avaliação requer decisões sobre a aprendizagem e o desenvolvimento dos educandos. Mas nem sempre é esse o significado no contexto da escola, sendo comum ocorrer apenas a verificação da retenção de conteúdos.

A avaliação deve se caracterizar como um instrumento capaz de estabelecer as condições de aprendizagem do aluno e sua relação com o ensino. Seus procedimentos devem permitir uma análise do desempenho pedagógico, oferecendo subsídios para o planejamento e a aplicação de novas estratégias de ensino que permitam alcançar o objetivo determinado pelo professor em cada conteúdo específico.

Atualmente, com a política de educação inclusiva assumida pelo Ministério da Educação do Brasil, impulsionado por um movimento mundial contra os processos de exclusão, o debate sobre formas de 
atendimento ao aluno com deficiência tem-se intensificado na direção de uma pedagogia inclusiva, que busque atender esses alunos nas classes comuns do ensino regular (Oliveira, 2003).

A inclusão tem sido entendida como um princípio que impulsiona um novo paradigma no atendimento ao aluno com deficiência: o paradigma de suporte (Aranha, 2000). O debate sobre esse princípio se intensifica, no Brasil, a partir da Declaração de Salamanca e é consubstanciado nos documentos nacionais como a Lei de Diretrizes e Bases da Educação Nacional (LDB), em diversos pareceres e resoluções do Conselho Nacional de Educação e mesmo nos Parâmetros Curriculares Nacionais (PCN), os quais podemos considerar como a referência curricular que pretende direcionar a ação educativa a nível nacional.

Dessa forma, a questão da avaliação desponta como elemento essencial para direcionar a prática pedagógica, colocando em destaque o desempenho escolar desses alunos e a proposição de adaptações curriculares.

O princípio de inclusão deve fundamentar a prática pedagógica, resgatando a possibilidade de determinados educandos que, independentemente de suas condições, têm direito às mesmas oportunidades de realização de seu potencial psicossocial. No entanto, é preciso discutir as condições institucionais, administrativas e pedagógicas que poderão ou não concretizar esse princípio no cotidiano das escolas.

Com a proposta da inclusão, a escolaridade de alunos com deficiências deve-se dar em classes comuns; dessa forma as práticas educativas nas classes comuns e nas classes especiais devem ser revistas para possibilitar um atendimento adequado às necessidades especiais das crianças deficientes, sem que isto interfira do modo negativo no processo educacional das crianças comuns.

Neste contexto político-educacional, a avaliação das necessidades educacionais dos alunos com deficiência é elemento fundamental para subsidiar sua aprendizagem e assessorar o acompanhamento da escolarização desse aluno nas classes comuns, através da oferta dos recursos necessários para viabilizar o seu sucesso educacional. No entanto, a avaliação não pode restringir-se às suas condições de desenvolvimento bio-psico-social, mas também deve estabelecer o seu potencial de aprendizagem, inclusive o nível de competência curricular desse aluno, tendo como referência a proposta curricular da série onde está matriculado (Oliveira, Poker, 2003; Oliveira, Leite, 2000; Sebastian, 1999).

Os instrumentos de avaliação devem informar o desenvolvimento atual da criança, a forma como ela enfrenta determinadas situações de aprendizagem, os recursos e o processo que faz uso em determinada 
atividade. Conhecer o que ela é capaz de fazer, mesmo que com a mediação de outros, permite a elaboração de estratégias de ensino próprias e adequadas a cada aluno em particular.

$\mathrm{Na}$ educação especial, considerada pelo Conselho Nacional de Educação como modalidade de educação escolar, que assegura recursos e serviços educacionais "de modo a garantir a educação escolar e promover o desenvolvimento das potencialidades dos educandos que apresentam necessidades educacionais especiais" (Brasil, 2001, 2002), a avaliação deveria assumir características diferentes, uma vez que a proposta é atender as necessidades específicas de cada aluno, tendo como objetivo facilitar, garantir e oferecer oportunidades de escolarização para os alunos que não acompanham, por diversas razões, o ensino comum. ${ }^{1}$

No entanto, a avaliação do aproveitamento escolar do aluno com deficiência tem-se caracterizado como um processo complexo devido às especificidades de suas necessidades e de seu desenvolvimento, muitas vezes bastante diferenciado. As características específicas de alguns quadros de deficiência dificultam a avaliação pedagógica e o estabelecimento das adequações ou adaptações necessárias para se garantir a escolaridade desse aluno.

O habitual processo de avaliação diagnóstica não tem sido suficiente para estabelecer qual a forma de ensino mais adequada para atender essa clientela e como avaliar o seu potencial de aprendizagem. Os erros no procedimento diagnóstico, a inexistência de avaliação e acompanhamentos adequados vêm perpetuando uma série de equívocos quanto ao processo de ensino e aprendizagem desses alunos, essencialmente naqueles com deficiência mental.

De acordo com Ferreira (1994), no caso dos alunos com deficiência mental, nem sempre ficam claros os "ajustes" a serem feitos em termos de materiais, recursos, técnicas, currículos ou pessoal, necessários para garantir a sua aprendizagem e, conseqüentemente, os aspectos a serem analisados em uma avaliação educacional. Dessa forma, muitas vezes, a avaliação acaba por reduzir-se à busca de um diagnóstico que justifique a entrada do aluno em classe especial ou em instituições especializadas.

Educadores e pesquisadores em educação especial vêm discutindo os limites e a inadequação do sistema de avaliação diagnóstica e pedagógica, considerando-se a necessidade de acompanhamento dos

1 Na perspectiva de uma educação inclusiva, a educação especial se configura como uma rede de suporte capaz de assegurar a aprendizagem dos alunos com necessidades educacionais especiais, entre eles aqueles com deficiência, mesmo que através de métodos e recursos diferenciados. Seu objetivo deve ser o de facilitar a aprendizagem desses alunos, devendo ser encarada como uma extensão da educação comum. 
avanços educacionais desses sujeitos, seja nas instituições, nas classes especiais ou nas classes comuns.

Alguns autores vêm propondo alternativas para avaliar as condições de desenvolvimento dos alunos com deficiência, demonstrando a importância e a possibilidade de um processo avaliativo que forneça elementos para um planejamento pedagógico diretivo que responda às necessidades e possibilidades de cada aluno.

As alternativas variam como abordagens psicopedagógicas (Bassedas, E. et al., 1996), avaliação dinâmica com base em Vygotsky (Lunt, 1995), programas de facilitação de desenvolvimento para crianças deficientes (Fonseca, 1995), modelo diagnóstico-prescritivo (Glat, Kadlec, 1989) e outros.

O próprio Conselho Regional de Psicologia, com o intuito de modificar ou criar novas alternativas para projetos educacionais diferenciados, tem se proposto a rever a legislação sobre os encaminhamentos para educação especial, buscando alterações na participação dos psicólogos no processo de diagnóstico (São Paulo, 1997). Também tem promovido vários encontros para debater a educação inclusiva e o papel do psicólogo nessa nova perspectiva.

A discussão acerca da avaliação do desempenho escolar evidencia a necessidade de reflexão sobre formas alternativas de avaliar e conhecer o aluno, principalmente quando se refere ao aluno com deficiência, uma vez que outras variáveis estão diretamente relacionadas ao destino escolar desses sujeitos e até mesmo ao sucesso do aluno no ensino comum e ao alcance do término de sua escolaridade.

É importante ressaltar que a educação especial lida com diferenças substanciais entre as diversas categorias de deficiência (auditiva, física, mental e visual) e diferenças grandes entre pessoas de uma mesma categoria de deficiência, por exemplo, pessoas com deficiência mental (ou qualquer outra deficiência) possuem tantas diferenças entre si quanto pessoas comuns. Essas diferenças se relacionam a diversos aspectos desde individuais até socioeconômicos e culturais; portanto, estabelecer formas de avaliação comuns a todos os grupos não seria justificável dentro de níveis de desenvolvimento e aprendizagem tão amplamente diferenciados.

Como vemos, a avaliação educacional é extremamente complexa principalmente quando nos referimos aos alunos com deficiência. Assim, o objetivo desse trabalho foi analisar as representações sobre avaliação do rendimento escolar de alunos com deficiência de professores especializados. Também foram investigados quais os critérios e estratégias que caracterizam o processo de avaliação utilizado para subsidiar o 
trabalho pedagógico e as decisões sobre o destino escolar do aluno com deficiência.

\section{MÉTODO}

\section{Participantes}

- 79 professores do Ensino Fundamental assim distribuídos:

1) 30 professores do setor educacional da APAE/Marília

2) 24 professores de classes inclusivas ${ }^{2}$ do Ensino Fundamental

3) 25 professores de classes especiais ou sala de recursos, habilitados e atuando nas diferentes áreas de deficiência (auditiva, física, mental e visual).

\section{Materiais}

- Questionário com questões fechadas.

- Materiais de escritório em geral.

\section{Procedimentos para coleta e análise dos dados}

Inicialmente, procedemos a todas as etapas necessárias para elaboração do instrumento de coleta de dados, desde a leitura de estudos realizados sobre o tema, levantamento temático com professores especializados, discussão em grupo de pesquisa para adequação dos temas do questionário até a elaboração do questionário definitivo para coleta de dados.

Após a solicitação das autorizações pertinentes, as escolas foram visitadas e os questionários entregues aos professores selecionados pelos critérios referentes aos objetivos da pesquisa, e estabelecido um prazo de quinze dias para a devolução do material. Ao final do prazo, as pesquisadoras retornaram às escolas e, como foram entregues apenas alguns questionários, estabeleceram um novo prazo.

2 Estamos usando a terminologia "classes inclusivas" para indicar classes comuns que possuem alunos com deficiência inseridos nesse contexto do ensino regular, no interior de uma rede pública de ensino que estava iniciando o processo de implantação e implementação de uma Pedagogia Inclusiva. Bem sabemos que o ideal é que os sistemas de ensino sejam acolhedores e abertos à diferença, buscando a aprendizagem na diversidade, tornando desnecessário o uso de qualitativos para diferenciar serviços ou atendimentos específicos. 
A análise dos dados foi conduzida da seguinte forma: transcrição das entrevistas, leitura integral das respostas, organização das informações e recorte dos trechos significativos, elaboração do sistema provisório de categorias e categorização dos dados.

Após esse processo inicial, solicitamos a contribuição de quatro consultores independentes para codificar as respostas de cada sujeito e analisar a consistência do sistema provisório de categorias analíticas. Realizamos, então, o cálculo dos índices de concordância e verificamos o índice de 50\% em algumas categorias, o qual consideramos insuficiente, exigindo a revisão do sistema de categorias.

Re-elaboramos as categorias e refizemos a classificação das respostas dos entrevistados, submetemos o material, novamente, à análise de consultores. Os índices de concordância, nessa segunda etapa, oscilaram entre 75 a 100\%, considerados satisfatórios e indicando a objetividade da classificação realizada pelas pesquisadoras.

\section{RESULTADOS}

O objetivo dessa pesquisa era analisar a representação sobre o rendimento escolar do aluno com deficiência de professores que atuam diretamente com esse aluno, seja nos serviços especiais, seja em classes comuns em sistemas educacionais inclusivos.

Dos 79 questionários distribuídos, foram devolvidos 39, sendo 16 de professores do ensino especial (classe especial ou sala de recursos), 10 de classes inclusivas e 13 da APAE, representando 49,3\% da amostra. Dos professores de classes inclusivas, dois responderam em dupla, portanto seus questionários foram excluídos da análise dos dados, perfazendo um total de 37 questionários $(46,8 \%)$. Demonstramos a seguir a caracterização da amostra:

Tabela 1: Caracterização dos professores participantes da pesquisa

\begin{tabular}{c|c|c|c|c|c|c|c|c|c}
\hline \multicolumn{9}{c|}{ Formação } & \multicolumn{4}{c}{ Atuação } \\
\hline \multirow{2}{*}{ EM } & \multicolumn{2}{|c|}{ ES } & \multicolumn{4}{c|}{ EE } & \multicolumn{3}{c}{ Modalidade de ensino } \\
\cline { 2 - 10 } & Ped. & Outras & DA & DF & DM & DV & CI & CE & APAE \\
\hline 02 & 18 & 1 & 3 & 3 & 8 & 2 & 8 & 16 & 13 \\
\hline
\end{tabular}

Legenda: EM - ensino médio; ES - ensino superior; EE - educação especial; Ped. - pedagogia; DA - def. auditiva; DF - def. física; DM - def. mental; DV - def. visual; CI - classe inclusiva; CE - classe especial. 
Em relação à formação dos professores, temos um quadro bastante otimista, uma vez que de 37 professores entrevistados, 34 possuem o curso superior em Pedagogia, 01 em Letras, e 16 possuem formação específica em educação especial, nas diferentes áreas da deficiência. É importante ressaltar que 15 são formados pela Unesp e um pela PUC, duas universidades bem conceituadas, tanto do ponto de vista do ensino quanto da pesquisa. Todos os entrevistados são do gênero feminino ${ }^{3}$.

Também é preciso apontar que, no caso das professoras do Ensino Fundamental, elas estavam trabalhando com alunos com deficiência em uma proposta inclusiva; portanto, não era esperado que tivessem habilitação específica, uma vez que as especificidades da deficiência seriam trabalhadas em salas de recursos.

Após a análise das respostas obtidas por meio dos questionários e uma classificação inicial em categorias, as respostas dos sujeitos foram submetidas à avaliação por cinco consultores para estabelecimento do índice de concordância, sendo três pesquisadores da área de educação especial e dois alunos do curso de Pedagogia, um com habilitação em deficiência física e outro em deficiência mental. Os índices de concordância, conforme mencionado anteriormente, oscilaram entre 75 e $100 \%$.

Foram elaboradas 11 questões relacionadas com o tema, que buscavam identificar as representações dos professores sobre avaliação educacional, rendimento escolar, procedimentos e critérios de avaliação e a especificidade da avaliação em educação especial.

$\mathrm{Na}$ questão 1 foi perguntado às professoras o que entendiam por avaliação educacional. Com base em suas respostas foram estabelecidas as seguintes categorias:

\section{Tabela 2: Caracterização das respostas dos professores sobre avaliação educacional}

\begin{tabular}{l|c|c}
\hline \multicolumn{1}{c|}{ Categorias } & F & \% \\
\hline 1) Acompanhamento do processo de ensino-aprendizagem & 32 & 86,5 \\
\hline 2) Verificação de objetivos e assimilação de conteúdos & 5 & 13,5 \\
\hline Total & 37 & 100,0 \\
\hline
\end{tabular}

\footnotetext{
${ }^{3}$ Considerando-se esse aspecto, usaremos o termo professoras no decorrer deste artigo.
} 
Como podemos observar, 32 professoras $(86,5 \%)$ entendem que a avaliação educacional está relacionada com o acompanhamento do processo de ensino e aprendizagem, considerando a avaliação como um processo bi-direcional, avalia o aluno e também os elementos inerentes ao processo de ensino, seja a didática do professor, a metodologia de aula, a organização dos conteúdos, em síntese, o planejamento de ensino na sua integralidade. Essa forma de conceber a avaliação educacional condiz com a abordagem de avaliação dinâmica que valoriza o processo e busca conhecer as estratégias utilizadas pelos alunos para a aprendizagem.

Por outro lado, também encontramos 5 professoras $(13,5 \%)$ que reduzem a avaliação à verificação dos conteúdos e ao alcance dos objetivos de ensino, enfatizando mais o produto do que o processo de aprendizagem e desconsiderando aspectos relevantes e indispensáveis da avaliação educacional.

A questão 2 buscou investigar como a avaliação se caracteriza em educação especial. Vejamos os resultados.

Tabela 3: Caracterização das respostas dos professores sobre avaliação em educação especial

\begin{tabular}{l|c|c}
\hline \multicolumn{1}{c|}{ Categorias } & F & \% \\
\hline 1) Igual ao ensino comum & 14 & 37,8 \\
\hline 2) Mais individualizada e específica que no ensino comum & 14 & 37,8 \\
\hline 3) Diagnóstica e multidisciplinar & 3 & 8,1 \\
\hline 4) Em educação especial os alunos não são avaliados & 1 & 2,7 \\
\hline 5) Não responderam a questão & 5 & 13,6 \\
\hline Total & 37 & 100,0 \\
\hline
\end{tabular}

É interessante observar como se configuram os dados nessa questão. As categorias 1 e 2 apresentam a mesma concentração dos dados, porém apontam formas diferentes de se perceber a avaliação em educação especial. Ao mesmo tempo em que é importante as professoras não perceberem diferenças entre a avaliação do aluno comum e a do aluno com deficiência, o que pode indicar uma ênfase maior no currículo e facilitar a inserção dos alunos com deficiência no contexto da classe comum, isso também pode indicar uma desconsideração das especificidades 
provenientes de algumas deficiências, trazendo como implicações dificuldades maiores para a aprendizagem desse aluno. Se pensarmos que alguns quadros de deficiência exigem ajustes e organizações diferentes para que se garanta a aprendizagem, e se não percebidas essas diferenças as mesmas não farão parte do planejamento do professor, considerar a avaliação em educação especial igual à do ensino comum pode prejudicar o desenvolvimento escolar do aluno com deficiência.

Por outro lado, a partir de uma proposta de educação inclusiva, o foco de avaliação passa a ser as necessidades educacionais específicas de cada aluno, seja ele deficiente ou não, com base no planejamento curricular determinado no projeto pedagógico de cada escola. Assim, há uma modificação importante no próprio conceito de deficiência, o qual se desloca de uma abordagem individual para uma abordagem interacionista que considera o papel do "outro" (ou da audiência) na identificação dos desvios, entre eles, o da deficiência. Dessa forma, há, sim, uma aproximação importante entre a avaliação pedagógica de alunos com e sem deficiência.

Nesta mesma questão, 14 professoras $(37,8 \%)$ responderam que a avaliação é igual ao ensino comum, porém, mais individualizada e específica. Incorremos no mesmo risco apontado anteriormente. Ao mesmo tempo em que é importante conhecer mais particularmente as necessidades dos alunos, inclusive aquelas relacionadas com a deficiência em si, não podemos perder o referencial pedagógico que é a proposta curricular da série onde o aluno está inserido.

Também encontramos 3 professoras $(8,1 \%)$ que consideram que a avaliação deve ser diagnóstica e multidisciplinar. De acordo com a Resolução do Conselho Estadual de Educação (São Paulo, 2002) a avaliação é, prioritariamente, pedagógica "realizada pela equipe da escola podendo, ainda, contar com o apoio de profissionais da área de saúde quanto aos aspectos físicos, motores, visuais, auditivos e psicossociais" (artigo $3^{\circ}$ ). Como vemos, as outras avaliações, embora de fundamental importância, possuem caráter complementar.

Um dado que nos preocupa é encontrar uma professora $(2,7 \%)$ que considera que os alunos com deficiência não precisam ser avaliados, distorcendo, por completo, a função dos serviços educacionais especializados, uma vez que essa professora, em particular, atua em classes especiais para deficientes mentais, o que pode levar a uma falsa compreensão das possibilidades escolares desses alunos e, conseqüentemente, a percepção que não precisam de avaliação. 
Na questão 3 investigamos a respeito do rendimento escolar.

Tabela 4: Caracterização das respostas dos professores sobre rendimento escolar

\begin{tabular}{l|c|c}
\hline \multicolumn{1}{c|}{ Categorias } & F & \% \\
\hline $\begin{array}{l}\text { 1) Verificação sistemática da prática educativa e do processo } \\
\text { de ensino-aprendizagem }\end{array}$ & 15 & 40,6 \\
\hline $\begin{array}{l}\text { Verificação sistemática da aprendizagem de determinados } \\
\text { conteúdos e/ou objetivos }\end{array}$ & 9 & 24,3 \\
\hline $\begin{array}{l}\text { Procedimento para padronizar os conhecimentos e } \\
\text { mensurar a aprendizagem }\end{array}$ & 6 & 16,2 \\
\hline 4) Não responderam a questão & 7 & 18,9 \\
\hline Total & 37 & 100,0 \\
\hline
\end{tabular}

Das trinta e sete professoras, $15(40,6 \%)$ responderam que é a verificação sistemática da prática educativa em relação ao acompanhamento do processo de ensino e aprendizagem, 9 (24,3\%) que é a verificação sistemática da prática educativa em relação à aprendizagem de determinados conteúdos e/ou objetivos, 6 (16,2\%) que é um procedimento para padronizar os conhecimentos e mensurar a aprendizagem e $7(18,9 \%)$ não responderam a questão.

As respostas se diferenciam substancialmente, oscilando desde uma visão ainda presa à padronização de conhecimentos e mensuração da aprendizagem até uma visão mais dinâmica que considera a prática educativa e o processo de ensino e aprendizagem como elementos também a serem avaliados, incluindo não apenas o aluno, mas o contexto de ensino em que se deu a aprendizagem.

$\mathrm{Na}$ questão 4 foi perguntado qual o propósito da avaliação do rendimento escolar em educação especial e quais os aspectos considerados. Vejamos os resultados. 
Tabela 5: Caracterização das respostas dos professores sobre rendimento escolar em educação especial

\begin{tabular}{ll|c|c}
\hline \multicolumn{1}{c|}{ Categorias } & F & $\%$ \\
\hline 1) & $\begin{array}{l}\text { Mesmo da educação comum: acompanhamento } \\
\text { sistemático do processo de ensino e aprendizagem }\end{array}$ & 24 & 64,9 \\
\hline 2) & $\begin{array}{l}\text { Mesmo da educação comum, mas com o objetivo de } \\
\text { diagnosticar as dificuldades e as diferenças individuais. }\end{array}$ & 9 & 24,3 \\
\hline 3) Não responderam a questão & 4 & 10,8 \\
\hline Total & 37 & 100,0 \\
\hline
\end{tabular}

De acordo com a tabela, 24 professoras $(64,9 \%)$ responderam que o rendimento escolar em educação especial tem os mesmos objetivos do ensino comum: o acompanhamento sistemático do processo de ensino e aprendizagem, 9 (24,3\%) que é o mesmo da educação comum, mas com o objetivo de diagnosticar dificuldades e diferenças individuais mais específicas, relacionadas com as deficiências e 4 (10,8\%) não responderam a questão.

Diante desses dados, pode-se observar que as professoras, no geral, estão preocupadas com a adequação do processo de ensino e aprendizagem às condições de seus alunos e dos objetivos e conteúdos a serem trabalhados e não somente com a classificação, verificação e atribuição de notas, independentemente da deficiência.

No entanto, 9 delas $(24,3 \%)$ enfatizam as dificuldades $\mathrm{e}$ necessidades individuais provenientes das deficiências, aspecto de extrema importância, pois, ao mesmo tempo em que não devemos focar a deficiência em si, não podemos incorrer no risco de negar condições de desenvolvimento e aprendizagem específicas aos alunos com deficiência, principalmente no que se refere ao uso de recursos necessários para possibilitar ao aluno o acesso ao currículo.

$\mathrm{Na}$ questão 5 foi perguntado se avaliam o rendimento escolar de seus alunos e quais são os aspectos considerados. Das 37 professoras, 35 $(94,6 \%)$ responderam que avaliam seus alunos e $2(5,4 \%)$ não responderam a questão. Os critérios considerados nessa avaliação estão apresentados na tabela 6, a seguir. 
Tabela 6: Aspectos considerados na avaliação do rendimento escolar do aluno com deficiência

\begin{tabular}{l|c|c}
\hline \multicolumn{1}{c|}{ Categorias } & F & \% \\
\hline 1) Conteúdos acadêmicos, aspectos pessoais e sociais. & 24 & 68,6 \\
\hline $\begin{array}{l}\text { 2) As necessidades educacionais específicas relacionadas às } \\
\text { deficiências }\end{array}$ & 7 & 20,0 \\
\hline 3) Retenção de conteúdos & 4 & 11,4 \\
\hline Total & 35 & 100,0 \\
\hline
\end{tabular}

Como podemos observar, das 35 que responderam que avaliam seus alunos, $24(68,6 \%)$ consideram os conteúdos acadêmicos, aspectos pessoais e sociais, $7(20 \%)$ as necessidades educacionais específicas relacionadas à deficiência, inclusive preparação para o trabalho e $4(11,4 \%)$ a retenção de conteúdos.

Podemos identificar que as professoras dão importância ao conteúdo acadêmico quando avaliam o aluno com deficiência, o que pode ser considerado um aspecto positivo, uma vez que também a esse aluno deve-se garantir a compreensão e apreensão dos conhecimentos trabalhados no contexto da sala de aula.

Com relação às necessidades educacionais específicas, citadas por 7 professoras (20\%) estão sendo considerados os aspectos socioemocionais e afetivos e a preparação para o trabalho. Acreditamos, porém, que esses aspectos também devem ser considerados na avaliação de todo os alunos, não se caracterizando, portanto, como específico da educação especial. É preocupante o fato de 4 professoras $(11,4 \%)$ citarem a retenção de conteúdos como critério de avaliação, pois isso restringe sobremaneira o olhar sobre as competências dos alunos, de qualquer aluno.

Na questão 6 foi perguntado qual a freqüência da avaliação. Encontramos 25 professoras $(67,6 \%)$ que fazem acompanhamento diário ou constante, $9(24,3 \%)$ que avaliam mensalmente ou bimestralmente, uma $(2,7 \%)$ que faz acompanhamento diário sistemático (com registro em fichas pessoais), uma (2,7\%) quando o aluno vai ser integrado e uma $(2,7 \%)$ não respondeu a questão. Podemos observar que a freqüência é bastante variada e a forma de registro também.

Na questão 7 foi perguntado às professoras quem solicita ou prevê a necessidade de avaliação. Encontramos as seguintes respostas. 
Tabela 7: Profissional responsável pela avaliação do aluno com deficiência

\begin{tabular}{l|c|c}
\hline \multicolumn{1}{c|}{ Categorias } & F & $\%$ \\
\hline 1) O próprio professor & 19 & 51,4 \\
\hline 2) A equipe pedagógica da escola & 11 & 29,7 \\
\hline $\begin{array}{l}\text { 3) A equipe da Diretoria Regional ou Secretaria Municipal } \\
\text { de Ensino }\end{array}$ & 4 & 10,8 \\
\hline 4) Não responderam a questão & 3 & 8,1 \\
\hline Total & 37 & 100,0 \\
\hline
\end{tabular}

Das 37 professoras questionadas, 19 (51,4\%) responderam que é o próprio professor o responsável pela avaliação do aluno com deficiência, 11 $(29,7 \%)$ remete à equipe pedagógica da escola, $4 \quad(10,8 \%)$ que é responsabilidade da equipe das Diretorias Regionais ou Secretarias Municipais de Ensino e 3 professoras (8,1\%) não responderam a questão.

A avaliação pedagógica em educação especial possui determinadas especificidades que dificultam a interpretação do professor acerca de sua operacionalização. Essas dificuldades podem ser pontuadas pelo próprio processo de construção da área de educação especial como uma área de conhecimento específico.

Historicamente, a interpretação da Pedagogia sobre as causas que levam algumas crianças a dificuldades escolares recebeu forte influência da medicina, ou melhor, do diagnóstico médico e, mais recentemente, do clínico (psicologia/fonoaudiologia) levando a uma "patologização" do fracasso escolar na busca de justificar as dificuldades escolares através de patologias ou de quadros clínicos individuais e intrínsecos que ocasionariam a dificuldade em aprender.

Essas idéias veiculadas historicamente trazem conseqüências para a avaliação pedagógica de alunos com deficiência, pois se suas dificuldades estão condicionadas às condições orgânicas incapacitadoras, como pode o professor avaliar a competência desses alunos? No entanto, "mais do que conhecer as patologias dos alunos e os limites de seu desenvolvimento", a avaliação deve enfatizar, seu nível de competência curricular, principalmente nesse momento em que vivenciamos o processo de inclusão pontuado como um novo paradigma educacional. "Assim, o referencial para avaliação pedagógica muda substancialmente e passa a ser o currículo" (Oliveira, 2002, p. 250). 
Essas mudanças, no pensar socioeducativo sobre o papel da avaliação em educação especial, são, muitas vezes, conflitantes e contraditórias e isso pode ser observado nas respostas das professoras pesquisadas, uma vez que algumas delas $(10,8 \%)$ ainda consideram que o foco de avaliação está "fora" da escola, remetendo-se à equipe técnica dos órgãos centrais da educação, perdendo o referencial pedagógico que é o currículo em toda sua dimensão.

$\mathrm{Na}$ questão 8 foi perguntado quais as decisões tomadas a partir da avaliação.

Tabela 8: Decisões tomadas a partir da avaliação pedagógica do aluno com deficiência

\begin{tabular}{l|c|c}
\hline \multicolumn{1}{c|}{ Categorias } & F & \% \\
\hline 1) Mudança de estratégias e de metodologia de ensino & 24 & 64,9 \\
\hline 2) Garantir a escolaridade & 4 & 10,8 \\
\hline 3) Integração na classe comum & 2 & 5,4 \\
\hline 4) Não responderam a questão & 7 & 18,9 \\
\hline Total & 37 & 100,0 \\
\hline
\end{tabular}

De acordo com os dados apresentados na tabela, 24 professoras $(64,9 \%)$ responderam que a avaliação pedagógica leva a mudanças de estratégias e da metodologia de ensino, desempenhando uma função extremamente importante do processo avaliativo, que considera não apenas o aluno, mas as condições que lhe são dadas para garantir a sua aprendizagem. Desse ponto de vista, a avaliação pedagógica de alunos com deficiência estaria em consonância com os objetivos gerais da avaliação de qualquer aluno.

Podemos observar, também, que 4 professoras $(10,8 \%)$ consideram que a partir da avaliação tenta-se garantir ao aluno com deficiência a escolaridade, seja através da transição de uma série para outra, seja através da evolução do estágio de aprendizagem desse aluno. Duas professoras $(5,4 \%)$ consideram que a avaliação fundamenta o processo de integração do aluno com deficiência para as classes comuns do ensino regular e $7(18,9 \%)$ não responderam a questão, fato que vemos com preocupação, pois pode indicar que o professor não tem muita clareza das decorrências do processo 
de avaliação ou, ainda, que não vê a necessidade de avaliar o aluno com deficiência.

Na questão 9 foi perguntado às professoras quais os problemas que vêm sendo identificados no processo de avaliação em educação especial.

Tabela 9: Problemas identificados pelas professoras no processo de avaliação em educação especial

\begin{tabular}{l|c|c}
\hline \multicolumn{1}{c|}{ Categorias } & $\mathbf{F}$ & $\%$ \\
\hline 1) Não identificam nenhum problema & 12 & 32,5 \\
\hline 2) Descaso do Estado para todo o Sistema de Ensino & 5 & 13,5 \\
\hline $\begin{array}{l}\text { 3) Falta de profissionais qualificados para avaliar as } \\
\text { especificidades }\end{array}$ & 4 & 10,8 \\
\hline $\begin{array}{l}\text { Equivalência do ensino comum, desconsiderando-se as } \\
\text { diferenças educativas dos alunos com deficiência }\end{array}$ & 3 & 8,1 \\
\hline 5) Distanciamento da família & 4 & 10,8 \\
\hline 6) Não responderam a questão & 9 & 24,3 \\
\hline Total & 37 & 100,0 \\
\hline
\end{tabular}

As respostas encontradas nessa questão são de interessante análise. O descaso do Estado para com o Sistema de Ensino é apontado por 5 professoras $(13,5 \%)$, assim como a falta de profissionais que pudessem prestar assessoria complementar no processo de avaliação, apontado por 4 professoras $(10,8 \%)$. Esse questionamento é muito pertinente porque caracteriza a forma como o sistema vem tratando os alunos com deficiência e denota a falta de acompanhamento dos órgãos responsáveis pela escolarização desses alunos. Embora a avaliação pedagógica tenha caráter curricular, não podemos desconsiderar sua dimensão multidisciplinar, o que exige, muitas vezes, a avaliação complementar realizada por outros profissionais que poderão colaborar na caracterização das necessidades específicas de certos alunos.

$\mathrm{Na}$ questão 10 foi perguntado às professoras se consideram satisfatório o processo de avaliação do rendimento escolar em educação especial, por que, e, se não, como deveria ser. De acordo com as respostas dos questionários, $23(62,2 \%)$ responderam que esse processo de avaliação é satisfatório, 10 (27\%) que não e 4 (10,8\%) não responderam. 
Das 23 que responderam que sim, 17 (74\%) responderam que é porque a avaliação assegura o acompanhamento sistemático do aluno, 3 $(13 \%)$ consideram que o professor tem liberdade na escolha de critérios e estratégias para avaliar e 3 (13\%) não responderam o porquê.

Das $10(27 \%)$ que responderam que não, $5(50 \%)$ acham que a avaliação deveria ser focalizada nas condições do aluno e na evolução da sala e que deveria ocorrer a valorização do professor, que está em contato direto com os alunos. Este é um fato relevante, pois, muitas vezes, os pais e outros profissionais ao encaminharem o aluno especial valorizam e consideram mais importante a avaliação diagnóstica de médicos e psicólogos do que as observações, percepções e indicações do professor da classe que tem mais chances de acompanhar o desenvolvimento do seu aluno. Uma professora (10\%) respondeu que a avaliação deveria ser multidisciplinar.

Nessa mesma questão uma professora não respondeu como deveria ser e outra sugeriu que os professores deveriam estudar mais sobre avaliação do aluno especial. Resposta que demonstra a preocupação e conhecimento da professora em relação à complexidade da avaliação pedagógica do aluno com deficiência.

Na questão 11 foi perguntado aos professores o que deveria ser avaliado e com qual propósito.

\section{Tabela 10: Objetivos da avaliação em educação especial}

\begin{tabular}{l|c|c}
\hline \multicolumn{1}{c|}{ Categorias } & F & \% \\
\hline 1) Todo o processo de ensino e aprendizagem & 15 & 40,6 \\
\hline $\begin{array}{l}\text { Aptidões gerais de cada um e aspectos específicos de } \\
\text { cada área de deficiência }\end{array}$ & 8 & 21,6 \\
\hline $\begin{array}{l}\text { Rendimento escolar para verificar os avanços e } \\
\text { dificuldades }\end{array}$ & 6 & 16,2 \\
\hline 4) O essencial para a integração & 4 & 10,8 \\
\hline 5) Não responderam a questão & 37 & 100,0 \\
\hline Total
\end{tabular}

Nessa questão, $15(40,6 \%)$ responderam que deveria ser avaliado todo o processo de ensino e aprendizagem subsidiando a reflexão da ação pedagógica, $8(21,6 \%)$ as aptidões gerais de cada um e aspectos específicos de cada área de deficiência, $6(16,2 \%)$ o rendimento escolar para verificar os 
avanços e dificuldades, $4(10,8 \%)$ o essencial para a integração e $4 \quad(10,8 \%)$ não responderam a questão.

A análise geral dos dados aponta que o conceito de avaliação educacional de 32 professoras (86,5\%) está ligado ao acompanhamento do processo de ensino e aprendizagem, considerando a avaliação um processo bi-direcional, caracterizando a avaliação como um momento de reflexão de todo o processo educacional, envolvendo o professor, o aluno e o contexto escolar.

A avaliação educacional em educação especial, para as professoras entrevistadas, é equivalente à do ensino comum, ainda que mais individualizada no sentido de identificar necessidades pessoais e específicas do aluno, tendo como objetivo elaborar um programa pedagógico individualizado. Também trazem considerações sobre o caráter diagnóstico e multidisciplinar da avaliação.

Quanto ao rendimento escolar no contexto geral da educação, as professoras entendem como a verificação sistemática da prática educativa em relação ao acompanhamento do processo de ensino e aprendizagem, a verificação da aprendizagem de determinados conteúdos e/ou objetivos e, algumas, ainda consideram a avaliação como um procedimento de padronização dos conhecimentos e uma forma de mensurar a aprendizagem.

No contexto da educação especial, o propósito da avaliação do rendimento escolar é percebido como o acompanhamento sistemático do processo de ensino e aprendizagem como na educação comum, mas também com o intuito de diagnosticar dificuldades e diferenças pessoais e a adequação de objetivos educacionais na busca de subsídios para a reflexão da prática do professor, da aprendizagem do aluno e da adequação do contexto escolar. Desta forma, "o processo avaliativo é de suma importância em todos os âmbitos do processo educacional para nortear as decisões pedagógicas e retro-alimentá-las, exercendo um papel essencial nas adaptações curriculares" (Brasil, 1999, p.57).

Os aspectos considerados na avaliação dos alunos com deficiência são bastante variados e complementares, uma vez que são avaliados os conteúdos acadêmicos, os aspectos pessoais, as necessidades educacionais específicas relacionadas à deficiência, os aspectos socioemocionais e afetivos, a preparação para o trabalho e a retenção de conteúdos.

A avaliação é realizada por meio de acompanhamento diário ou constante, não-sistemático e sistemático, e bimestralmente. É solicitada ou prevista primeiramente pelo próprio professor da classe e, algumas vezes, também por algum outro profissional da escola, da Diretoria Regional ou das Secretarias Municipais de Ensino. 
Segundo os Parâmetros Curriculares Nacionais - Adaptações Curriculares (Brasil, 1999), a avaliação do aluno com necessidades especiais deve focalizar:

"[...] os aspectos do desenvolvimento (biológico, intelectual, motor, emocional, social, comunicação e linguagem); o nível de competência curricular (capacidades do aluno em relação aos conteúdos curriculares anteriores e a serem desenvolvidos) $e$ o estilo de aprendizagem (motivação, capacidade de atenção, interesses acadêmicos, estratégias próprias de aprendizagem, tipos preferenciais de agrupamentos que facilitam a aprendizagem e condições físicas ambientais mais favoráveis para aprender)."

Relacionando as propostas apresentadas e a prática das professoras entrevistadas, os dados demonstram que, no cotidiano escolar, seja na instituição pesquisada ou no ensino fundamental, as professoras procuram avaliar de acordo com o proposto pelo Ministério da Educação.

Mesmo em relação ao contexto educacional, algumas professoras demonstram preocupação com o envolvimento de elementos significativos para a avaliação pedagógica: os alunos, os professores, as aulas, os objetivos curriculares e todo o contexto educacional, conforme o proposto pelos documentos oficiais.

"[...] o processo avaliativo deve focalizar: o contexto da aula (metodologias, procedimentos didáticos, atuação do professor, relações interpessoais, individualização do ensino, condições físico-ambientais, flexibilidade curricular etc.); o contexto escolar (projeto pedagógico, funcionamento da equipe docente e técnica, currículo, clima organizacional, gestão, etc.)." (Brasil, 1999, p.57)

Para essas professoras, o motivo da avaliação do aluno deficiente é o acompanhamento do processo de ensino-aprendizagem e a avaliação da aprendizagem do aluno, a fim de tomar algumas decisões como mudança de estratégias e metodologias de ensino, ou como forma de garantir a escolaridade do aluno.

Se assim for, o processo de avaliação utilizado, tanto por professoras da instituição especializada quanto do ensino fundamental, subsidia o trabalho pedagógico em educação especial. A avaliação tem sido utilizada para refletir e a partir desta reflexão tomar decisões sobre a respeito do processo educacional de seu aluno e de sua prática. Traz a idéia que a avaliação pedagógica deve envolver todo o trabalho escolar e 
"[...] servir como retroalimentação para o trabalho pedagógico, pois deve dar subsidios para o professor e para a equipe refletir sobre o desenvolvimento de todo o processo educacional, servindo de bússola que orienta as mudanças necessárias no curso da proposta curricular e nos planejamentos." (Ferreira, 1993, p.151)

A maior parte das professoras desse estudo não identifica problemas específicos na avaliação em educação especial, embora algumas apontem o descaso do Estado para com todo o Sistema de Ensino e a falta de profissionais nas Diretorias de Ensino para avaliar as diferenças e a equivalência com o ensino comum. Isso nos faz pensar que as professoras possuem plena consciência de que os alunos especiais podem estar junto com os outros, desde que suas diferenças não sejam menosprezadas ou esquecidas, uma vez que são elas que nos darão a dimensão das necessidades dos alunos e dos serviços que se farão necessários para garantir sua aprendizagem.

As professoras consideram satisfatório o processo de avaliação do rendimento escolar em educação especial porque assegura o acompanhamento sistemático do aluno e também pela liberdade garantida ao professor na escolha de critérios e estratégias para avaliarem seus alunos.

Algumas apontam e propõem que a avaliação deveria ser multidisciplinar, focalizada nas condições do aluno e em suas necessidades específicas, mas valorizando o professor da sala. De certa forma estão de acordo com a Resolução 95/00, do Conselho Estadual de Educação, que enfatiza a avaliação processual e pedagógica, mas também considera a importância da avaliação multidisciplinar como complementar, no sentido de estabelecer as necessidades dos alunos.

Atualmente está em discussão e em implantação o processo de inclusão educacional, tendo como fundamento uma "Escola para Todos", garantindo o acesso e a permanência na escola de grupos historicamente excluídos, entre eles, o dos alunos deficientes. Certamente ainda carecemos de ações e pesquisas para que a inclusão se torne uma proposta efetiva no interior das escolas e das políticas educacionais do sistema de ensino do país, uma vez que

"[...].o princípio fundamental da escola inclusiva é o de que todas as crianças deveriam aprender juntas, independentemente de quaisquer dificuldades ou diferenças que possam ter. As escolas inclusivas devem reconhecer e responder as diversas necessidades de seus alunos, acomodando tanto estilos como ritmos diferentes de aprendizagem e assegurando uma educação de qualidade a todos por meio de currículo apropriado, modificações organizacionais, estratégias de ensino, 
uso de recursos e parcerias com a comunidade [...] dentro das escolas inclusivas, as crianças com necessidades especiais deveriam receber qualquer apoio extra que possam precisar, para que se lhes assegure uma educação efetiva." (Unesco, 1994, p.61)

Para que isso ocorra os alunos precisam ser avaliados em todos os aspectos (acadêmicos, psicológicos, sociais, físicos, etc.) e, quando necessário, realizar adequações específicas para garantir sua aprendizagem. Estas adaptações podem ser significativas ou não e devem ocorrer em todas as dimensões necessárias, no projeto pedagógico da escola, no currículo da sala de aula ou podem ter caráter individual (Brasil, 1999). O papel das adaptações curriculares é a busca de

"[...] soluções para as necessidades específicas do aluno, e não o fracasso na viabilização do processo de ensino-aprendizagem. As demandas escolares precisam ser ajustadas, para favorecer a inclusão do aluno. É importante observar que as adaptações focalizam as capacidades, o potencial, e não centralizam nas deficiências e limitações do aluno, como tradicionalmente ocorria." (Brasil, 1999, p.38)

Ao compararmos os dados encontrados nesse estudo, entre os diferentes grupos de professoras, observamos que não ocorreram diferenças significativas nos resultados, o que nos leva a inferir que seja nas instituições especializadas, nas classes especiais, ou seja, nas classes comuns, ao avaliar os alunos com deficiência, as preocupações das professoras parecem transitar sobre os mesmos aspectos, salvo pequenas diferenças marcadas pelos objetivos específicos dos recursos educacionais dos quais os alunos são usuários.

\section{CONSIDERAÇÕES FINAIS}

A avaliação escolar tem-se apresentado como um dos componentes curriculares de maior importância na questão educacional em razão do seu significado no processo de ensino e aprendizagem. A busca de procedimentos adequados para acompanhar a escolaridade do aluno com deficiência está na pauta das preocupações dos professores ${ }^{4}$, uma vez que

4 Nesta parte do artigo estamos nos referindo aos professores em geral, por isso que nos referimos no masculino. Estamos considerando que os dados, embora específicos e sem possibilidade de generalizações, apontam tendências significativas no pensar do professor sobre o processo de avaliação. 
depende disto para que o atendimento educacional melhore e responda às suas necessidades específicas.

O professor parece ter incorporado novas concepções de avaliação encarando-a como uma mediação entre o ato de aprender e ensinar. Dessa forma, a avaliação pedagógica "deverá indicar caminhos para a ação educacional" (Oliveira, Leite, 2000, p. 18) e, assim, a análise do processo de ensino e aprendizagem inclui novos elementos na compreensão das condições educacionais, dos quais podemos enfatizar: o aluno, o professor, a escola e as condições que são oferecidas para a aprendizagem.

Encaramos isso como um avanço. A prática cotidiana parece incorporar as análises advindas de pesquisas educacionais de cunho científico e, hoje, podemos localizar no discurso do professor os elementos teóricos tão debatidos no interior das universidades. Bem sabemos que pode, ainda, estar apenas no discurso politicamente correto, na fala que ressoa positivamente nos meios acadêmicos. No entanto, isso é parte do processo, verbalizar também significa dar-se conta da complexidade do ato de avaliar e de novos elementos que darão um melhor contorno na discussão sobre avaliação.

A avaliação pedagógica em educação especial, embora deva caminhar em parceria com a educação comum, possui determinadas especificidades, próprias das condições dos alunos pelos quais se responsabiliza, que nos obriga a um olhar mais apurado para também, mas não exclusivamente, identificar as necessidades específicas do aluno com deficiência proporcionando-lhes os recursos dos quais dependem para acessar o currículo.

A discussão acerca da operacionalização de uma educação inclusiva também confere um lugar de destaque à avaliação pedagógica e influencia o pensar do professor. Mais do que conhecer as patologias dos alunos e os limites de seu desenvolvimento, o processo de inclusão enfatiza as condições de aprendizagem desses alunos e o seu nível de competência curricular. Assim, o referencial para a avaliação pedagógica é o currículo da série onde o aluno está matriculado.

Nesse contexto, e prevendo que os alunos deverão estar juntos, independentemente de suas condições primeiras (sejam deficientes ou não), no processo de inclusão os objetivos da avaliação pedagógica são:

"Determinar a necessidade educacional do aluno, tomar decisões sobre sua escolarização, elaborar propostas de adaptações curriculares, propor adaptações significativas (se necessárias), determinar recursos e apoios à sua necessidade, e também determinar tanto o seu estilo de aprendizagem quanto o estilo de ensino do professor." (Oliveira, Leite, 2000, p. 17) 
Neste estudo, as professoras entrevistadas têm uma concepção bastante diversificada de avaliação educacional; algumas a concebem como simplesmente uma verificação da assimilação de conteúdos e de objetivos específicos, buscando o acompanhamento educacional do aluno, outras consideram que a avaliação do aluno deficiente deve ser igual à do ensino comum.

De qualquer forma, o rendimento escolar representa a verificação sistemática da prática educativa em relação a aprendizagens de determinados conteúdos e objetivos e na educação especial deve ser equivalente ao ensino comum, porém com o objetivo de diagnosticar dificuldades e diferenças pessoais específicas intrinsecamente relacionadas com a deficiência.

Os critérios, as estratégias e o processo de avaliação do rendimento escolar utilizado pelas professoras das classes especiais referem-se, principalmente, aos aspectos acadêmicos, levando-se em consideração os conteúdos ensinados e os aspectos pessoais da deficiência; avaliação realizada diariamente pelo próprio professor da sala, o que é muito significativo, por meio da solicitação e da necessidade desse mesmo professor.

O processo de avaliação utilizado parece subsidiar o trabalho pedagógico do professor de educação especial, pois o motivo da avaliação do rendimento escolar, para as professoras entrevistadas, é o acompanhamento do processo educacional e a partir disso mudar as estratégias e as metodologias de ensino. Apontam a necessidade de ser avaliado todo o processo que envolva o ensino e a aprendizagem: ensino, alunos, professores, profissionais envolvidos e familiares, elemento preponderante na educação especial.

Em educação especial poderíamos citar dois eixos importantes no que se refere aos objetivos da avaliação:

1. Avaliação específica: que busca estabelecer a capacidade de desenvolvimento do aluno, mediante a identificação de suas necessidades individuais e específicas para decidir em relação ao encaminhamento para os serviços de educação especial que ele necessita e acerca dos procedimentos ou recursos especiais para aprendizagem.

2. Avaliação compreensiva ou de acompanhamento: que busca a análise do desempenho escolar e curricular do aluno, por meio de um instrumento de avaliação (elaborado pelo próprio professor) para conhecer as condições de aprendizagem dos alunos, a sua competência curricular e 
estabelecer estratégias de ensino, recursos e procedimentos de apoio para subsidiar o planejamento pedagógico.

Essas duas dimensões da avaliação em educação especial poderão esclarecer a necessidade de procedimentos específicos para $o$ acompanhamento da trajetória escolar do aluno. Ao mesmo tempo em que não podemos dispensar o conhecimento acerca do desenvolvimento biopsico-social do aluno com deficiência, não podemos negligenciar o acompanhamento pedagógico e curricular, o específico do olhar pedagógico e escolar.

O processo de avaliação não pode mais compactuar com uma visão protecionista e assistencialista da deficiência, uma vez que

"Ele não precisa de nossa proteção, mas de ferramentas para conduzir-se em um mundo como o nosso onde, dia-a-dia, as pessoas enfrentam conflitos, frustrações. Ele precisa ter a possibilidade de sobreviver em um mundo competitivo; mesmo por ter suas limitações, é preciso investir mais na sua formação, não é só passar o tempo, é necessário preparação." (Rojas, 1997, p. 41)

Certamente, a educação especial tem um importante papel a desempenhar perante os alunos com deficiência, e a avaliação educacional é parte fundamental desse processo, pois é por meio da avaliação que estaremos traçando as necessidades e possibilidades desses alunos.

\section{REFERÊNCIAS BIBLIOGRÁFICAS}

ALENCAR, M. L. et al. Avaliação e intervenção em classes especiais. Ensaio, v.2, n.1, p.63-78, out./dez. 1994.

ARANHA, M. S. F. Inclusão social e municipalização. In: MANZINI, E. J. Educação especial: temas atuais. Marília: Unesp, 2000.

BASSEDAS, E. et al. Intervenção educativa e diagnóstico psicopedagógico. Porto Alegre: Artes Médicas, 1996.

BRASIL. Lei de Diretrizes e Bases da Educação Nacional: nova LDB. (Lei n. 9.394/96). Rio de Janeiro: Qualitymark, 1997.

BRASIL. Secretaria de Educação Fundamental. Parâmetros Curriculares Nacionais: adaptações curriculares. Brasília: MEC/SEF/SEESP, 1999. 
BRASIL. Conselho Nacional de Educação. Câmara de Educação Básica. Diretrizes Nacionais para a Educação Especial na Educação Básica. Parecer CEB. Relator: Kuno Paulo Rhoden e Sylvia Figueiredo Gôuvea.17 set. 2001.

BRASIL. Conselho Nacional de Educação. Câmara de Educação Básica. Diretrizes Nacionais para a Educação Especial na Educação Básica. Resolução CNE/CEB n. 2, 2001. Disponível em: htpp://www.mec.gov.br/ cne/ftp/ceb/ceb0201-doc. Acesso em: 06.03.2002.

CARVALHO, R. E. Avaliação e atendimento em educação especial. Temas em Educação Especial II. São Carlos: UFSCar, 1993.

CENP/SEESP. Declaração de Salamanca e linha de ação sobre necessidades de Educação Especial. Brasília: Unesco/Corde, 1994.

Educação especial. Brasília: CENP/SEESP, 1994

FERREIRA, I. N. Caminhos do aprender: uma alternativa educacional para a criança portadora de deficiência mental. Brasília: Coordenação Nacional para Integração da Pessoa Portadora de Deficiência, 1993.

FERREIRA, J. R. A Exclusão da diferença: a educação do portador de deficiência. Piracicaba: Unimep, 1994.

FONSECA, V. Educação especial - programa de estimulação precoce: uma introdução às idéias de Feurstein. Porto Alegre: Artes Médicas, 1995.

GLAT, R.; KALLEC, V. P. S. A Criança e as suas deficiências: métodos e técnicas de atuação psicopedagógica. São Paulo: Agir, 1989.

HOFFMAN, J. M. L. Avaliação: mito e desafio - uma perspectiva construtivista. Porto Alegre: Mediação, 1991.

LUCKESI, C. C. Verificação ou avaliação: o que pratica a escola? A Construção do professor de ensino e a avaliação. Idéias, n. 8, p. 71-80. São Paulo: FDE, 1990.

LUNT, I. A prática da avaliação. In: DANIELS, H. Vygotsky em foco: pressupostos e desdobramentos. Campinas: Papirus, 1995.

OLIVEIRA, A. A. S. Educação inclusiva: concepções teóricas e relato de experiência. In: MARQUEZINE, M. C. et al (org.). Inclusão. Londrina: Eduel, 2003. 
OLIVEIRA, A. A. S. Representações sociais sobre educação especial e deficiência: o ponto de vista de alunos deficientes e professores especializados. Marília, 2002. Tese (dout. em Educação) - Universidade Estadual Paulista/Faculdade de Filosofia e Ciências.

OLIVEIRA, A. A. S.; POKER, R.B. Educação inclusiva e municipalização: a experiência em educação especial de Paraguaçu Paulista. Revista Brasileira de Educação Especial, v.8, n.2, 2003.

OLIVEIRA, A. A. S.; LEITE, L. P. Educação inclusiva e as necessidades educativas especiais. In: MANZINI, E. J. Educação especial: temas atuais. Marília: Unesp, 2000.

ROJAS, M. F. Independência na adolescência e vida adulta. Temas sobre desenvolvimento, v.6, n.35, São Paulo: Memnon, 1997.

SÃO PAULO. Conselho Estadual de Educação. Diretrizes curriculares para a Educação Básica no Estado de São Paulo. São Paulo: CEE, 2002.

SÃO PAULO. Conselho Regional de Psicologia. Princípios norteadores para atuação psicológica e educação especial. São Paulo: CRP, $6^{a}$ região, 1997. (mimeo)

SEBASTIÁN, E. H. Necesidades educativas especiales y adaptaciones curriculares. Manual de Referência. Guadalajara: CIDEAS, 1999 (mimeo)

SOUSA, C. P. (org.) Avaliação do rendimento escolar. Campinas: Papirus, 1995.

UNESCO. Final Report on the World Conference on Special Needs Education: access and quality. Salamanca: Ministry of Education and Science, 1994.

Recebido em: junho 2004

Aprovado para publicação em: novembro 2004 
